\title{
Patients' preferences for nutrition-related health outcomes in liver disease: a preliminary study using an electronic questionnaire
}

G.K. Nowson, Madden, A.M. (2014) Patients' preferences for nutrition-related health outcomes in liver disease: a preliminary study using an electronic questionnaire. J. Hum. Nutr. Diet. 27(x):xx-xx doi: DOI: 10.1111/jhn.12214

http://onlinelibrary.wiley.com/doi/10.1111/jhn.12214/abstract

Key words: Liver diseases; nutrition; patient preference; outcome and process assessment.

Authors: Gemma K. Nowson ${ }^{1,2}$, Angela M. Madden ${ }^{1}$

Work undertaken in the Department of Human and Environmental Sciences, University of Hertfordshire, Hatfield AL10 9AB

Present addresses:

${ }^{1}$ Department of Human and Environmental Sciences, University of Hertfordshire, Hatfield, AL10 9AB, UK

${ }^{2}$ Hertfordshire Community NHS Trust, Lister Hospital, Stevenage, UK

Corresponding author: Dr Angela Madden, Department of Human and Environmental Sciences, University of Hertfordshire, Hatfield AL10 9AB; telephone 01707 281385; email a.madden@herts.ac.uk

Role of authors:

Gemma Nowson contributed to data collection, designed and undertook data analysis and co-wrote the manuscript;

Angela Madden contributed the original idea, designed the study, supervised the data collection and analysis and co-wrote the manuscript.

All authors approved the final manuscript.

Conflicts of interests: The authors declare that they have no conflict of interests

Funding: No funding was received for undertaking this study. 


\section{Abstract}

Background: Patients with liver disease frequently have nutritional problems but intervening to improve these is challenging. Healthcare interventions that respond to patients' needs are associated with better health outcomes but no studies investigating patients' preferences for nutrition-related outcomes in liver disease have been published. The aim of this study was to identify nutrition-related health outcomes that are important to patients with liver disease.

Methodology: An electronic questionnaire was devised and reviewed by patients and dietitians with relevant experience. It comprised Likert scale and open questions focussing on six domains considered pertinent to patients with liver disease. An invitation to participate was posted on the website of a national liver charity and sent to liver patient support groups.

Results: Fifty-one patients participated (22 men / 29 women). Responses indicated a wide range of preferred nutrition-related outcomes with those identified as very important most frequently focussing on gaining knowledge about which foods to eat more or less of, and on understanding why nutrition is important in liver disease. Women tended to score outcomes as more important than did men. Participants who considered themselves overweight scored outcomes on body size and shape as more important than those with other nutritional problems. Additional outcomes were identified and included increased knowledge of healthy eating, interactions between medication and food, and supplementation.

Conclusions: The study identified a wide range of nutrition-related outcomes that were important to this small sample of patients with liver disease and these may be useful to guide the direction of future nutrition-related management. 


\section{Introduction}

The prevalence of under nutrition and obesity is high in patients with chronic liver disease and is frequently associated with an impaired outcome (Alberino et al., 2001; Adams \& Lindor, 2007; Merli et al., 2010). Many patients, therefore, have the potential to benefit from nutritional interventions. However in this patient population, it is hard to identify improved outcomes that explicitly relate to nutritional interventions because of the complexity and heterogeneity of the patients, their clinical condition and other concomitant treatment (Devlin \& Appleby, 2010). These reasons combined with interventions that have not always been robustly designed, have contributed to the failure to clearly identify the benefits of nutrition support in patients with liver disease (Koretz et al., 2012). Although there is a need to evaluate health outcomes, there is evidence that some healthcare professionals are reluctant to use outcome measures due to a lack of knowledge and organisational support, limited time and perceived irrelevance to their patients (Duncan \& Murray, 2012).

Taking patients' preferences into account may help to identify areas on which to focus nutrition interventions and this is compatible with current health strategies (Department of Health, 2010). It has been recognised that in order to achieve good outcomes in patient care, it is essential to involve patients in decision-making (Department of Health, 2009; Department of Health, 2010; UK Government, 2012). To facilitate this, interest has grown in patient reported outcome measures (PROMs) which identify health outcomes that are valued by the patient. PROMs enable the effectiveness of care to be assessed from a patient's perspective (Haywood et al., 2006; Department of Health, 2008; Devlin \& Appleby, 2010; NHS Information Centre for Health and Social Care, 2010). 
PROMs were introduced in 2006 and have been used to compare assessments of variables such as mobility and pain after elective surgery, creating a measure of effectiveness of treatment (Devlin \& Appleby, 2010; British Dietetic Association, 2011). Their use has also been explored in chronic conditions including cancer, diabetes and respiratory medicine (Hogg et al., 2012; Worth et al., 2012; Corner et al., 2013; Jahagirdar et al., 2013) but reports of specifically nutrition or dietaryrelated PROMS are limited (Jackson et al., 2005). However, a study exploring the impact of diabetes on 18 life domains found that patients identified the most important aspect of their treatment as dietary freedom (Bradley \& Speight, 2002). This contrasted with the views of medical staff who underestimated the value of treatment leading to dietary freedom and overestimated the negative impact of having multiple insulin injections. This illustrates the need to evaluate treatment from a patient perspective and to explore patients' preferences for the outcomes that are most important to them. The aim of this study was to identify nutrition-related health outcomes that are important to patients with liver disease and could be used to inform dietetic management. 


\section{Methods}

\section{Questionnaire}

A questionnaire was designed based on the outcome domains described by the British Dietetic Association (2011) and clinical experience from a dietitian who had specialised in working with patients with liver disease. A draft version was circulated for consultation to liver patients and staff via the British Liver Trust and dietitians via the British Dietetic Association Gastroenterology Specialist Group. Minor amendments were made following feedback and an electronic version developed (Bristol Online Surveys, Bristol, UK). The final questionnaire comprised six domains and each listed between six and eleven outcomes. Participants were asked to score the importance of each of these using a Likert scale ranging from very important (5), to not important at all (1), and to provide additional comments or suggestions relating to outcomes in each domain (Appendix A). The questionnaire ended with closed questions asking about liver diagnosis selected from a list of 21 (British Liver Trust, 2012), length of illness, nutritional problems, age, gender and whether they lived in the UK and if English was their first language.

\section{Participants}

An invitation to participate was posted on the British Liver Trust website asking potential participants to access the online questionnaire via a link on the home page (British Liver Trust, 2013). After 10 weeks, the number of completed questionnaires was reviewed and due to the small number, the recruitment strategy was revised. The support groups listed on the British Liver Trust website were contacted by email or telephone and their members invited to participate. An invitation and link to the online questionnaire was also posted on UK-based liver disease groups on the social 
media site, Facebook. Paper copies of the questionnaire and stamped-addressed return envelopes were sent to potential participants who requested this in preference to using the online version. The participant information explained that the questionnaire was designed for adults with liver disease but responses from family, friends and healthcare professionals were also welcome providing that they were aged 18 years or older.

\section{Analysis}

Responses from the online and paper questionnaires were collated using a predefined protocol. Numerical results were analysed using SPSS version 20 (IBM, Chicago). The median score for each outcome was calculated to determine preference. The percentage of participants who scored very important for each individual outcome was calculated and from these values, the mean percentage for each domain was determined. As data were ordinal, non-parametric tests, Mann Whitney $U$ (2 sub-groups) and Kruskal Wallis ( $\geq 3$ sub-groups) (Argyrous, 2011), were used to identify whether there was a significant difference in median scores for each outcome between sub-groups of participants by gender, nutritional problem (collapsed into two categories) and liver disease type. Free-text responses were analysed using framework analysis (Richie \& Spencer, 1994), a structured approach which allows for the production of outcomes and the inclusion of a priori and emerging themes (Pope \& Mays, 2006). The stages used included familiarisation, identifying a thematic framework, indexing and identifying specific pieces of data that correspond to the themes (Lacey \& Luff, 2007). 
Ethical approval to undertake this study, including the revised recruitment process, was obtained from the Health and Emergency Professions Ethics Committee at the University of Hertfordshire (reference number: HEPEC10/11/9). 


\section{Results}

Sixty-eight responses were received. These included 51 from patients with liver disease (22 men / 29 women) with reported ages of $19-75$ years (mean $54.1 \pm 14.5$ ). Sixty-three percent of patient responses were provided online and the remainder used paper copies of the questionnaire. Patients reported suffering from liver disease for a mean of $8.8 \pm 4.4$ years and identified their diagnosis against 13 liver conditions including haemochromatosis ( $26 \%$ of participants), autoimmune hepatitis (12\%) and fatty liver / non-alcoholic steatohepatitis (10\%). The most frequently reported main nutritional problems were overweight (39\%) and trying to follow a special diet (12\%) whilst $22 \%$ reported no nutritional problems (Figure 1). Sixty-one percent of patients felt that nutrition was very important in liver disease. Only one patient indicated that they felt in perfect health on the day they completed the questionnaire, one reported that they were very ill and the remainder described their health on that day as somewhere in between these two extremes. Twenty-eight percent of patients reported that they had seen a dietitian for advice on their condition and $35 \%$ had received advice from elsewhere, including healthcare professionals, other patients and websites. In addition to the patients, five carers, seven healthcare professionals and five others also responded. The latter included a relative who was not a carer and an asymptomatic person with hepatitis $C$ who did not categorise themselves as a patient. Due to the small numbers and incomplete responses from the non-patients, these were analysed only qualitatively.

Patients' preference of health outcomes in six domains

Overall, outcomes in the domains 'eating and drinking' and 'helping you feel better' were rated very important more frequently than those in other domains with a mean 
number of responses in the highest category of $52 \%$ and $51 \%$ respectively (Table 1 ). The three individual outcomes with the highest number of very important responses (between $70-75 \%$ ) all came from the 'eating and drinking' domain. The outcomes in the domains, 'changing what you can do' and 'body size and shape' were rated very important less frequently than those in the other domains but still had a mean number of responses in the highest category of $34 \%$ and $33 \%$ respectively. The two individual outcomes with the smallest number of very important responses were 'my clothes will fit better as I have gained weight' (17\%) and 'I will increase my overall intake of food' (18\%). Female patients rated all outcomes as more important than did male patients and for $22(40 \%)$ individual outcomes the difference was significant (Table 1). Responses describing nutritional problems were collapsed into two groups, [overweight] and [underweight and difficulty eating], and patients describing no nutritional problems, following a special diet or other nutritional problems were omitted from this sub-group analysis. Overweight participants generally scored outcomes as more important than those who were underweight / had difficulty eating and these were significantly different for six (11\%) outcomes, five of which were in the 'body shape and size' domain (Table 2). Comparisons of preferred outcomes between patients with different conditions were varied and did not indicate any trends, probably because of the small numbers in most sub-groups.

\section{Additional outcomes identified by all participants}

Fifty-three additional comments relating to other nutrition-related outcomes or ways that a dietitian could help were provided by patients, carers, healthcare professionals and others not specified. Most comments related to 'eating and drinking' (45\%), 'practical issues' (15\%) or 'body shape and size' (15\%) and from these, several 
additional broad themes emerged and are illustrated below with quotations in italics (see also Appendix B):

a) 'I will have increased knowledge of healthy eating'. Participants reported that guidance from a dietitian would be beneficial on various aspects such as portion sizes, reducing salt, reading labels, time of meals, recipes and devising meal plans: "I would like to have a diet which includes snacks as I find I get hungry during the evenings and I don't want to eat the wrong food"

b) 'I will have an awareness of interactions between medication and food'. Some participants demonstrated relevant knowledge and understanding of specific issues: "e.g. steriods [sic] and increasing calcium, being on azathoprine and Vit D (avoid the sun if you're on Aza).

c) 'I will gain knowledge on supplementation'. Participants highlighted that advice on when and how to take supplements would be useful:

"Should I be taking vitamin supplements ?"

d) 'I will be able to manage my liver disease alongside my other conditions'. Several participants had other medical conditions such as diabetes or gastrointestinal problems and wanted to be able to make appropriate and practical food choices:

One carer asked "If there are any specific foods that might help with balancing sugar levels"

e) 'I will learn how to maintain weight'. Patients reported that they often struggled to keep their weight stable, whether this was losing weight or gaining weight:

"I lose weight very easily and have to be careful; sometimes advice in that direction would be helpful" 
f) 'I will achieve a more positive body image'. Combining exercise and fitness with food-related information was mentioned:

"If you look fit, you feel fit so it becomes easier to eat better as you feel you [sic] making a difference"

g) 'I will have increased confidence'. Several participants reported having future goals of going on holiday or going out to eat with family:

"To give me confidence and information to go and eat meals out with my family for birthday treats etc". 


\section{Discussion}

Patient involvement in decisions about their management is considered central to current UK healthcare (Department of Health, 2012) and so exploring their opinions about nutrition-related health outcomes is important for both dietitians and those commissioning their services. This study aimed to find out what nutrition-related health outcomes are important to patients with liver disease. The results indicate that a wide range of outcomes were described as very important by different participants but, notably, none of the proposed outcomes were considered to be of very little importance by all respondents. Awareness of this diversity of preferences by practitioners might help them to tailor their approach during consultations. The high rating given to 'having knowledge about foods to eat more or less of' and 'understanding the role of nutrition in liver disease' indicates that more of the participants of this study considered cognitive aspects very important than outcomes relating to function and body shape. Knowledge and understanding are considered to be important for patient empowerment which allows them to make their own decisions (Anderson \& Funnell, 2010). If knowledge and understanding are to be used as effective outcome measures, they need to be assessed robustly using a relevant and valid tool, for example a specific quiz or questionnaire. This approach has been taken to assess nutritional knowledge in patients with diabetes, renal disease and hypertension (Nicolucci et al., 2000; Ashurst \& Dobbie, 2003; Wong et al., 2013) and, in addition to assessing the effectiveness of interventions, is recognised as a pedagogic device to enhance learning (Kibble et al., 2011). The disadvantages of focussing on knowledge and understanding include that these may be more important to motivated patients with higher levels of education and viewed as less applicable to a wider range of individuals (Zoellner et al., 2011; Carbone \& 
Zoellner, 2012). It is likely that the patient population in the current study was already motivated because they were using a website related to their condition and / or engaged with a patient support group. Another important disadvantage associated with focussing predominantly on knowledge and understanding is that improvements in these areas are not necessarily followed by changes in dietary behaviour that will lead to health benefits (Giguère et al., 2012). It could be argued that for patients preferring outcomes based on knowledge and understanding to those related to behaviour change, this choice should be recognised by both healthcare professionals and those commissioning dietetic services even though this may not feel satisfactory from a health improvement perspective.

Use of behavioural strategies, like setting goals, is considered an important part of a dietetic consultation (Cullen et al., 2001), and this was recognised by the participants' responses to questions in the domain, 'the experience of seeing a dietitian'. Interestingly, goal setting was viewed as very important by different proportions of participants depending on whether this was undertaken as a partnership between the patient and dietitian, by the patient alone or by the dietitian alone (rated very important by $60 \%, 46 \%$ and $30 \%$ of participants respectively). Whilst more people in the study population preferred a partnership approach, others also valued setting goals themselves independently or being given these. These differences in preference for a partnership-led, patient-led or practitioner-led approach have been reported previously in an exploration of patients' experience of dietetic consultations (Hancock et al., 2012) and indicate the importance of the dietitian establishing what is preferred by the individual in each consultation. 
Functional and anthropometric measures have been suggested as potential objective and repeatable ways of assessing the outcome of a dietetic consultation (British Dietetic Association, 2011). In this study, these outcomes were considered very important by less than half of patients overall but by a greater proportion of those who were overweight. This difference indicates again the need to address each patient's needs individually rather than to place high value on measures that may be considered more useful to practitioners than patients.

Addressing symptoms, such as tiredness and sleep, was also rated as very important by the majority of patients and although these are likely to vary depending on clinical condition, are in agreement with standard dietetic practice to usually address symptoms (Johnson \& Bishop, 2007; British Dietetic Association, 2012). The challenges associated with measuring these symptoms to assess efficacy of dietetic management are that they will be influenced by many other factors beyond the control of the dietitian and nutritional intervention, and so whilst very important to many patients, they may not provide a specific tool for using in nutrition.

The small number of participants restricted sub-group analysis to gender differences and nutritional problems. The rating of outcomes as more important by female patients compared to men is consistent with research that has found that men are less likely to express their health needs and seek help from health services than women (Galdas et al., 2005). This finding suggests that dietitians, who comprise more women than men, should consider their patients' gender when discussing outcome preferences (Pollard et al., 2008). Differences in preferences between overweight participants and those who were underweight or reported difficulty eating 
were not unexpected but the small numbers in these sub-groups (23 and 10 respectively) indicate that the results should be interpreted with care and further exploration of these differences could be a useful area for future study.

There are several limitations to this study. Sampling using an online invitation or via a patient support group rather than through organised healthcare channels was undertaken for convenience, economy, to cover a wide geographical area and to ensure the research was independent from specific healthcare providers. However, is likely to have resulted in bias due to the self-selection of more motivated and ITliterate participants who may not have been representative of all patients with liver disease (Wright, 2005; Couper, 2007). Future studies could explore this area by recruiting participants directly from liver services using face-to-face or paper-based invitation. Using online invitation to recruit participants did not allow verification that those who responded were liver patients, their carers or healthcare professionals so there is a possibility that some responses may not have been from the intended population. Although no responses overtly suggested that this was the case, this problem has been recognised (Pulman \& Taylor, 2012). The questionnaire was designed with input from a small number of liver patients and dietitians and included both closed and open questions to try and capture a range of responses. This could have been improved by more patient involvement in the design, for example, by using a patient focus group to elicit topics for inclusion (Nicklin et al., 2010). Despite extending the recruitment process, the final sample size was smaller than anticipated and this has been reported in other surveys conducted online (Cook et al., 2000). Participants may have been discouraged by the length of the questionnaire ( $>60$ questions) and although there is evidence of better response rates from shorter 
questionnaires, these may reduce the amount and value of information obtained (Mathers et al., 2007; Zimmermann, 2010). The inclusion of a different patient group or healthy volunteers in future studies would allow comparison and identify whether responses reported in this study are specific to patients with liver disease.

In conclusion, this study has identified that a wide range of nutrition-related health outcomes were important to this sample of patients with liver disease and that preferences differed with gender and nutritional problem. Although the study is small and has methodological limitations, this is the first report of patient preferences in this area and supports the concept that dietitians should work with individual patients to identify their preferred health outcomes. 


\section{Acknowledgements}

The authors thank the patients who participated in the survey, the support group leaders who facilitated distribution of the questionnaires, staff at the British Liver

Trust and British Dietetic Association and liver and gastroenterology dietitians who contributed to the study design. 


\section{References}

Adams, L.A. \& Lindor, K.D. (2007) Nonalcoholic fatty liver disease. Ann. Epidemiol 17, 863-869.

Alberino, F., Gatta, A., Amodio, P., Merkel, C., Di Pascoli, L., Boffo, G. \& Caregaro, L. (2001) Nutrition and survival in patients with liver cirrhosis. Nutrition 17, 445-450.

Anderson, R.M. \& Funnell, M.M. (2010) Patient empowerment: myths and misconceptions. Patient Educ. Couns 79, 277-282.

Argyrous, G. (2011) Statistics for Research, London: SAGE Publications.

Ashurst, I.d.B. \& Dobbie, H. (2003) A randomised controlled trial of an educational intervention to improve phosphate levels in haemodialysis patients. J. Ren. Nutr 13, 267-274.

Bradley, C. \& Speight, J. (2002) Patient perceptions of diabetes and diabetes therapy: assessing quality of life. Diabetes Metab. Res. Rev 18, S64-S69.

British Dietetic Association. (2011) Model for dietetic outcomes. Retrieved 10 August 2013 from: http://www.bda.uk.com/publications/BDAOutcomesModel.pdf

British Dietetic Association. (2012) Model and process for nutrition and dietetic practice. Retrieved 10 August 2013 from:

http://members.bda.uk.com/profdev/profpractice/modeldieteticpractice/ModelProcess DieteticPractice.pdf

British Liver Trust. (2012) Liver conditions. Retrieved 14 January 2013 from: http://www.britishlivertrust.org.uk/home/the-liver/liver-diseases.aspx

British Liver Trust. (2013) British Liver Trust. Retrieved 18 August 2013 from: http://www.britishlivertrust.org.uk/

Carbone, E.T. \& Zoellner, J.M. (2012) Nutrition and health literacy: a systematic review to inform nutrition research and practice. J. Acad. Nutr. Diet 112, 254-265.

Cook, C., Heath, F. \& Thompson, R.L. (2000) A meta-analysis of response rates in web- or internet-based surveys. Educational Psychological Measurement 60, 821836.

Corner, J., Wagland, R., Glaser, A. \& Richards, S.M. (2013) Qualitative analysis of patients' feedback from a PROMs survey of cancer patients in England. B.M.J Open 3, e002316.

Couper, M.P. (2007) Issues of representation in ehealth research (with a focus on web surveys). Am. J. Prev. Med 32, S83-S89.

Cullen, K.W. \& Baranowski, T. \& Smith, S.P. (2001) Using goal setting as a strategy for dietary behavior change. J. Am. Diet. Assoc. 101, 562-566.

Department of Health. (2008) Guidance on the routine collection of patient-reported outcome measures (PROMs), London: Department of Health.

Department of Health. (2009) NHS 2010-2015: from good to great, preventative, people centred, productive, Norwich: The Stationary Office.

Department of Health. (2010) Equity and Excellence: Liberating the NHS, Norwich: The Stationary Office. 
Department of Health. (2012) Liberating the NHS: No decision about me, without me. Retrieved 15 December 2013, from:

https://www.gov.uk/government/uploads/system/uploads/attachment data/file/21698 0/Liberating-the-NHS-No-decision-about-me-without-me-Government-response.pdf

Devlin, N.J. \& Appleby, J. (2010) Getting the most out of PROMs. Putting outcomes at the heart of NHS decision-making, London: The Kings Fund.

Duncan, E.A.S. \& Murray, J. (2012) The barriers and facilitators to routine outcome measurement by allied healthcare professionals in practice: a systematic review. BMC Health Serv. Res 12, 96.

Galdas, P., Cheater, F. \& Marshall, P. (2005) Men and health help-seeking behaviour: literature review. J. Adv. Nurs 49, 616-623.

Giguère, A., Légaré, F., Grimshaw, J., Turcotte, S., Fiander, M., Grudniewicz, A., Makosso-Kallyth, S., Wolf, F.M., Farmer, A.P. \& Gagnon, M.P. (2012) Printed educational materials: effects on professional practice and healthcare outcomes. Cochrane Database Syst. Rev 10, CD004398.

Hancock. R.E., Bonner, G., Hollingdale, R. \& Madden, A.M. (2012) 'If you listen to me properly, I feel good': a qualitative examination of patient experiences of dietetic consultations. J. Hum. Nutr. Diet 25, 275-284.

Haywood, K., Marshall, S. \& Fitzpatrick, R. (2006) Patient participation in the consultation process: a structured review of intervention strategies. Patient Educ. Couns 63, 12-23.

Hogg. F.R., Peach, G., Price, P., Thompson, M.M. \& Hinchliffe, R.J. (2012) Measures of health-related quality of life in diabetes-related foot disease: a systematic review. Diabetologia 55, 552-65.

Jackson, J.A., Kinn, S. \& Dalgarno, P. (2005). Patient-centred outcomes measures in dietary research. J. Hum. Nutr. Diet 18, 83-92.

Jahagirdar, D., Kroll, T., Ritchie, K. \& Wyke, S. (2013) Patient-reported outcome measures for chronic obstructive pulmonary disease : the exclusion of people with low literacy skills and learning disabilities. Patient 6, 11-21.

Johnson, J. \& Bishop, J. (2007) Liver and biliary disease. In: Manual of Dietetic Practice, eds. B. Thomas \& J. Bishop, pp. 386-398. Oxford: Blackwell Publishing Ltd.

Kibble, J.D., Johnson, T.R., Khalil, M.K., Nelson, L.D., Riggs, G.H., Borrero, J.L. \& Payer, A.F. (2011) Insights gained from the analysis of performance and participation in online formative assessment. Teach. Learn. Med 23, 125-9.

Koretz, R.L., Avenell, A. \& Lipman, T.O. (2012) Nutritional support for liver disease. Cochrane Database Syst Rev 16, CD008344.

Lacey, A. \& Luff, D. (2007) Qualitative research analysis, Trent: RDSU.

Mathers, N., Fox, N. \& Hunn, A. (2007) Surveys and questionnaires, Trent: RDSU.

Merli, M., Giusto, M., Gentili, F., Novelli, G., Ferretti, G., Riggio, O., Corradini, S.G., Siciliano, M., Farcomeni, A., Attili, A.F., Berloco, P. \& Rossi, M. (2010) Nutritional status: its influence on the outcome of patients undergoing liver transplantation. Liver Int 30, 208-214. 
NHS Information Centre for Health and Social Care (2010) Patient reported outcome measures (PROMs). Retrieved 30 December 2012, from:

http://www.ic.nhs.uk/services/patient-reported-outcomes-measuresproms

Nicklin, J., Cramp, F., Kirwan, J., Urban, M. \& Hewlett, S. (2010) Collaboration with patients in the design of patient-reported outcome measures: capturing the experience of fatigue in rheumatoid arthritis. Arthritis Care Res 62, 1552-1558.

Nicolucci, A., Ciccarone, E., Consoli, A., Di Martino, G., La Penna, G., Latorre, A., Pandolfi, A., Vitacolonna, E. \& Capani, F. (2000) Relationship between patient practice-oriented knowledge and metabolic control in intensively treated type 1 diabetic patients: Results of the validation of the Knowledge and Practices Diabetes Questionnaire. Diabetes Nutr. Metab 13, 276-283.

Pollard, P., Taylor, M., Daher, N. \& Davis, N. (2008) Sex differences in health care: the compensation experience of registered dietitians. Health Care Manag 27, 259268.

Pope, C. \& Mays, N. (2006) Qualitative research in health care ( ${ }^{\text {rd }}$ ed.) Oxford: Blackwell Publishing Ltd.

Pulman, A. \& Taylor, J. (2012) Munchausen by internet: current research and future directions. J. Med. Internet Res 14, e115.

Richie, J. \& Spencer, L. (1994) Qualitative data analysis for applied policy research. In: Analysing Qualitative Data, eds. A. Bryman, \& R.G. Burgess, pp. 173-194. London: Routledge.

UK Government. (2012) Health and Social Care Act 2012, Norwich: The Stationary Office.

Wong, C.L., Arcand, J., Mendoza, J., Henson, S.J., Qi, Y., Lou, W. \& L'Abbé, M.R. (2013) Consumer attitudes and understanding of low-sodium claims on food: an analysis of healthy and hypertensive individuals. Am. J. Clin. Nutr. 97, 1288-1298.

Worth, A., Hammersley, V.S., Nurmatov, U., Sheikh, A. (2012) Systematic literature review and evaluation of patient reported outcome measures (PROMs) for asthma and related allergic diseases. Prim. Care. Respir. J 21, 455-458.

Wright, K.B. (2005) Researching internet-based populations: Advantages and disadvantages of online survey research, online questionnaire authoring software packages and web survey services. J. Computer-Mediated Communication, 10, 3.

Zimmermann, C. (2010) Ultra-short PROMs: clever or not? Br. J. Cancer. 9, 14771478.

Zoellner, J., You, W., Connell, C., Smith-Ray, R.L., Allen, K., Tucker, K.L, Davy, B.M. \& Estabrooks, P. (2011) Health literacy is associated with healthy eating index scores and sugar-sweetened beverage intake: findings from the rural Lower Mississippi Delta. J. Am. Diet. Assoc 111, 1012-1020. 


\section{Table 1}

Outcome preferences of 51 patients with liver disease, presented in six domains

\begin{tabular}{|c|c|c|}
\hline Outcome & Median score & $\begin{array}{l}\text { Respondents } \\
\text { scoring 'very } \\
\text { important' (\%) }\end{array}$ \\
\hline \multicolumn{3}{|c|}{ Eating and drinking (52\%) } \\
\hline I will know what foods I should eat less of* & \multirow{5}{*}{5} & 75 \\
\hline I will know what foods I should eat more of & & 72 \\
\hline I will understand why nutrition is important in liver disease* & & 70 \\
\hline I will understand why food is important to my health & & 64 \\
\hline I will feel more confident about selecting food ${ }^{\star}$ & & 63 \\
\hline I will reduce my intake of specific foods* & \multirow{2}{*}{4} & 43 \\
\hline I will worry less about eating & & 36 \\
\hline I will enjoy my food more & \multirow{2}{*}{3} & 30 \\
\hline I will increase my overall intake of food ${ }^{*}$ & & 18 \\
\hline \multicolumn{3}{|c|}{ Helping you to feel better ( $51 \%)$} \\
\hline I will feel less tired & \multirow{6}{*}{5} & 63 \\
\hline I will sleep better & & 61 \\
\hline Overall, I will feel better able to cope* & & 60 \\
\hline I will be stronger if I need surgery in the future * & & 60 \\
\hline I will be able to concentrate better & & 60 \\
\hline My skin will be less itchy* & & 52 \\
\hline I will need less medication* & 4.5 & 50 \\
\hline I will feel better able to cope with nausea* & \multirow{2}{*}{4} & 44 \\
\hline My appetite will improve & & 35 \\
\hline I will have less diarrhoea & 3.5 & 37 \\
\hline I will have less constipation* & 3 & 37 \\
\hline \multicolumn{3}{|c|}{ The experience of seeing a dietitian (47\%) } \\
\hline Together, the dietitian and I will set nutrition goals* & \multirow{5}{*}{5} & 60 \\
\hline I will learn new information from the dietitian & & 57 \\
\hline I will feel confident in managing my condition & & 57 \\
\hline I will receive useful written information about my diet ${ }^{*}$ & & 56 \\
\hline I will be pleased with my progress* & & 52 \\
\hline I will set my own goals for good nutrition & \multirow{6}{*}{4} & 46 \\
\hline I will feel reassured* & & 46 \\
\hline I will be able to do something differently* & & 41 \\
\hline The dietitian will be pleased with my progress ${ }^{*}$ & & 37 \\
\hline Other health staff will be pleased with my progress* & & 31 \\
\hline The dietitian will set nutrition goals for me & & 30 \\
\hline
\end{tabular}


Table 1, continued

\begin{tabular}{|c|c|c|}
\hline Outcome & Median score & $\begin{array}{l}\text { Respondents } \\
\text { scoring 'very } \\
\text { important' (\%) }\end{array}$ \\
\hline \multicolumn{3}{|l|}{ Practical issues (43\%) } \\
\hline I will know which foods to buy that will suit me & \multirow{2}{*}{5} & 61 \\
\hline I will know the best way to cook food for me & & 57 \\
\hline $\begin{array}{l}\text { I will know how and when to take vitamin and mineral } \\
\text { supplements }\end{array}$ & \multirow{3}{*}{4} & 45 \\
\hline $\begin{array}{l}\text { I will know how and when to take dietary supplements, e.g. } \\
\text { nourishing drinks }\end{array}$ & & 42 \\
\hline I will know how to eat well on a budget & & 30 \\
\hline I will know how and when to take my tube feed & 2.5 & 24 \\
\hline \multicolumn{3}{|l|}{ Changing what you can do (34\%) } \\
\hline My muscles will be stronger & \multirow{5}{*}{4} & 47 \\
\hline I will have enough energy to be able to enjoy my spare time* & & 44 \\
\hline $\begin{array}{l}\text { I will have enough energy to be able to socialise or go on } \\
\text { holiday }\end{array}$ & & 42 \\
\hline I will be able to look after my family & & 35 \\
\hline I will be able to leave the house & & 30 \\
\hline I will be able to walk to the bathroom without help* & \multirow{3}{*}{3} & 29 \\
\hline I will be able to do my own cooking and cleaning & & 25 \\
\hline I will be able to get a job / return to work & & 22 \\
\hline \multicolumn{3}{|l|}{ Body size and shape (33\%) } \\
\hline $\begin{array}{l}\text { I will be ready for other treatment that might be needed for my } \\
\text { liver condition }\end{array}$ & 5 & 55 \\
\hline My waist circumference will reduce due to fat loss & \multirow{6}{*}{4} & 42 \\
\hline My feet and ankles will be less swollen & & 39 \\
\hline I will lose weight due to reducing excess body fat & & 35 \\
\hline I will lose weight due to reducing excess fluid & & 35 \\
\hline My waist circumference will reduce due to fluid loss* & & 33 \\
\hline My clothes will fit better as I have lost weight & & 28 \\
\hline My arm muscles will increase in size & \multirow{2}{*}{3} & 24 \\
\hline I will gain flesh weight (not fluid) ${ }^{\star}$ & & 20 \\
\hline My clothes will fit better as I have gained weight & 2 & 17 \\
\hline
\end{tabular}

Scores presented as median (range) values where 5 = 'very important' and $1=$ 'not important at all'.

The average percentage of respondents scoring individual outcomes as 'very important' is presented in bold (\%) for each domain.

*Outcomes rated as significantly more important by female patients compared to male patients, $\mathrm{P}<0.5$. 


\section{Table 2}

Differences in outcome preference by nutritional problem

\begin{tabular}{|l|c|c|c|}
\hline Outcome & $\begin{array}{c}\text { Underweight \& } \\
\text { difficulty eating } \\
(\mathrm{n}=10)\end{array}$ & $\begin{array}{c}\text { Overweight } \\
(\mathrm{n}=23)\end{array}$ & P value \\
\hline \multicolumn{3}{|c|}{ Body size and shape } \\
\hline $\begin{array}{l}\text { My waist circumference will reduce due } \\
\text { to fat loss }\end{array}$ & $2(1-5)$ & $5(1-5)$ & 0.005 \\
\hline $\begin{array}{l}\text { I will lose weight due to reducing excess } \\
\text { body fat }\end{array}$ & $2(1-5)$ & $4(1-5)$ & 0.001 \\
\hline $\begin{array}{l}\text { I will lose weight due to reducing excess } \\
\text { fluid }\end{array}$ & $2.5(1-5)$ & $4(1-5)$ & 0.004 \\
\hline $\begin{array}{l}\text { My clothes will fit better as I have lost } \\
\text { weight }\end{array}$ & $2(1-4)$ & $4(3-5)$ & 0.000 \\
\hline I will gain flesh weight (not fluid) & $4(2-5)$ & $3(1-5)$ & 0.049 \\
\hline \multicolumn{4}{|c|}{ Changing what you can do } \\
\hline I will be able to leave the house & $5(2-5)$ & $3(1-5)$ & 0.028 \\
\hline
\end{tabular}

Scores presented as median (range) where $5=$ 'very important' and $1=$ 'not important at all'. 


\section{Figure 1}

Nutritional problems reported by 51 patients with liver disease

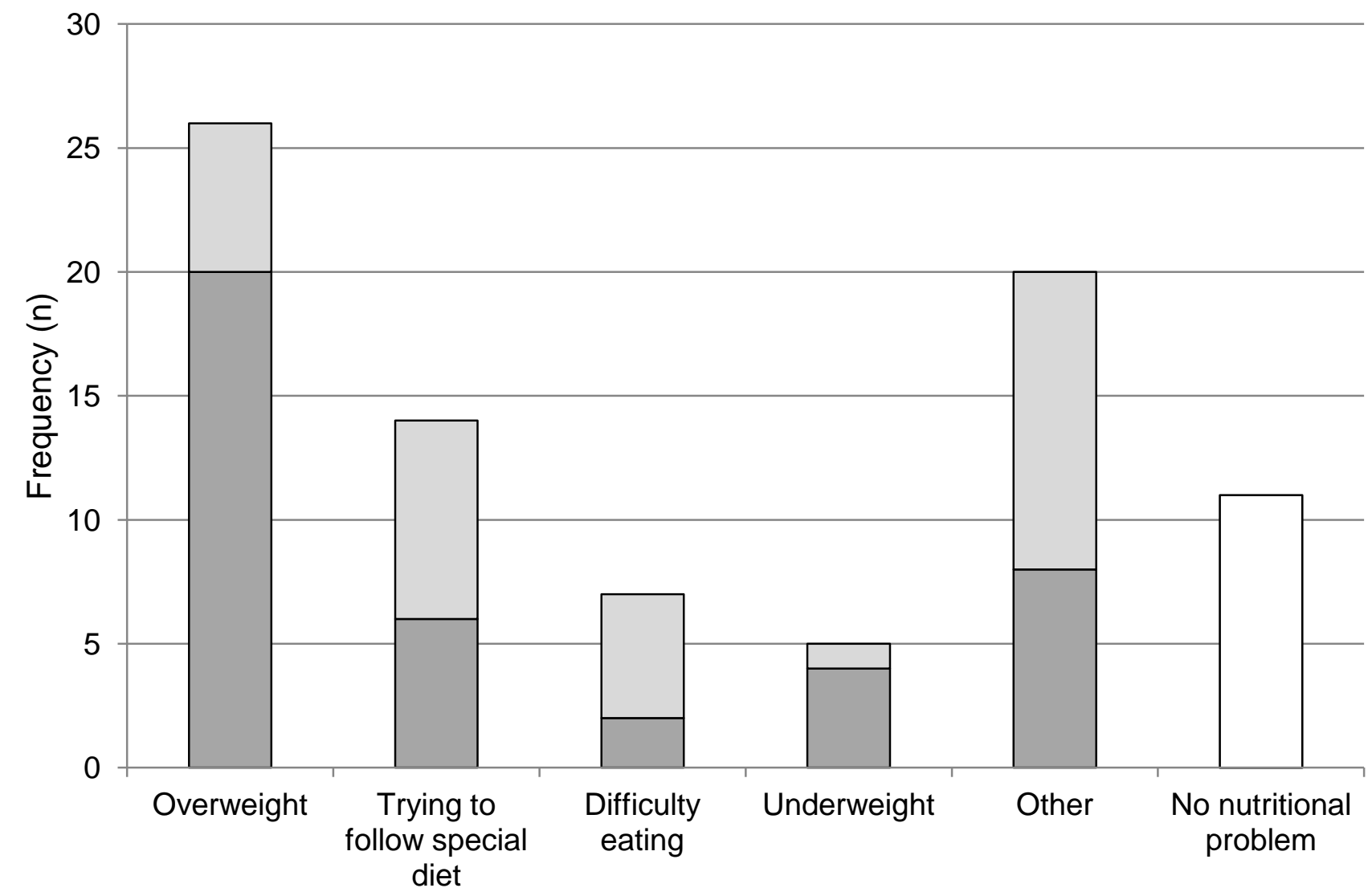

$\square$ Second nutritional problem

$\square$ Main nutritional problem 


\section{Appendix A}

\section{Selection of questions from the original questionnaire including the six domains and patient demographic information}

\section{Domain 1: Eating and drinking}

\begin{tabular}{|c|c|c|c|c|c|}
\hline \multirow[b]{2}{*}{ Outcome after seeing a dietitian ... } & \multicolumn{5}{|c|}{ How important is this outcome? } \\
\hline & $\begin{array}{c}\text { Not } \\
\text { at all } \\
1\end{array}$ & 2 & 3 & 4 & $\begin{array}{c}\text { Very } \\
5\end{array}$ \\
\hline \multicolumn{6}{|l|}{ 1. I will know what foods I should eat more of } \\
\hline \multicolumn{6}{|l|}{ 2. I will know what foods I should eat less of } \\
\hline \multicolumn{6}{|l|}{ 3. I will understand why food is important to my health } \\
\hline \multicolumn{6}{|l|}{$\begin{array}{l}\text { 4. I will understand why nutrition is important in liver } \\
\text { disease }\end{array}$} \\
\hline \multicolumn{6}{|l|}{ 5. I will increase my overall intake of food } \\
\hline \multicolumn{6}{|l|}{ 6. I will reduce my intake of specific foods } \\
\hline \multicolumn{6}{|l|}{ 7. I will worry less about eating } \\
\hline \multicolumn{6}{|l|}{ 8. I will enjoy my food more } \\
\hline 9. I will feel more confident about selecting food & & & & & \\
\hline
\end{tabular}

Domain 2: Practical issues, e.g. shopping and cooking

\begin{tabular}{|c|c|c|c|c|c|}
\hline \multirow[b]{2}{*}{ Outcome after seeing a dietitian ... } & \multicolumn{5}{|c|}{ How important is this outcome? } \\
\hline & $\begin{array}{c}\text { Not } \\
\text { at all } \\
1\end{array}$ & 2 & 3 & 4 & $\begin{array}{c}\text { Very } \\
5\end{array}$ \\
\hline 1. I will know the best way to cook food for me & & & & & \\
\hline 2. I will know which foods to buy that will suit me & & & & & \\
\hline 3. I will know how to eat well on a budget & & & & & \\
\hline $\begin{array}{l}\text { 4. I will know how and when to take dietary supplements, } \\
\text { e.g. nourishing drinks }\end{array}$ & & & & & \\
\hline $\begin{array}{l}\text { 5. I will know how and when to take vitamin and mineral } \\
\text { supplements }\end{array}$ & & & & & \\
\hline 6. I will know how and when to take my tube feed & & & & & \\
\hline
\end{tabular}


Domain 3: Body size and shape

\begin{tabular}{|c|c|c|c|c|c|}
\hline \multirow[b]{2}{*}{ Outcome after seeing a dietitian ... } & \multicolumn{5}{|c|}{ How important is this outcome? } \\
\hline & $\begin{array}{c}\text { Not } \\
\text { at all } \\
1\end{array}$ & 2 & 3 & 4 & $\begin{array}{c}\text { Very } \\
5\end{array}$ \\
\hline 1. I will gain flesh weight (not fluid) & & & & & \\
\hline 2. I will lose weight due to reducing excess body fat & & & & & \\
\hline 3. I will lose weight due to reducing excess fluid & & & & & \\
\hline $\begin{array}{l}\text { 4. I will be ready for other treatment that might be needed } \\
\text { for my liver condition }\end{array}$ & & & & & \\
\hline 5. My waist circumference will reduce due to fat loss & & & & & \\
\hline 6. My waist circumference will reduce due to fluid loss & & & & & \\
\hline 7. My arm muscles will increase in size & & & & & \\
\hline 8. My feet and ankles will be less swollen & & & & & \\
\hline 9. My clothes will fit better as I have lost weight & & & & & \\
\hline 10. My clothes will fit better as I have gained weight & & & & & \\
\hline
\end{tabular}

\section{Domain 4: Changing what you can do}

\begin{tabular}{|c|c|c|c|c|c|}
\hline \multirow[b]{2}{*}{ Outcome after seeing a dietitian ... } & \multicolumn{5}{|c|}{ How important is this outcome? } \\
\hline & $\begin{array}{c}\text { Not } \\
\text { at all } \\
1 \\
\end{array}$ & 2 & 3 & 4 & $\begin{array}{c}\text { Very } \\
5\end{array}$ \\
\hline 1. My muscles will be stronger & & & & & \\
\hline 2. I will be able to walk to the bathroom without help & & & & & \\
\hline 3. I will be able to do my own cooking and cleaning & & & & & \\
\hline 4. I will be able to leave the house & & & & & \\
\hline 5. I will be able to look after my family & & & & & \\
\hline 6. I will be able to get a job / return to work & & & & & \\
\hline $\begin{array}{l}\text { 7. I will have enough energy to be able to enjoy my spare } \\
\text { time }\end{array}$ & & & & & \\
\hline $\begin{array}{l}\text { 8. I will have enough energy to be able to socialise or go } \\
\text { on holiday }\end{array}$ & & & & & \\
\hline
\end{tabular}


Domain 5: Helping you to feel better

\begin{tabular}{|c|c|c|c|c|c|}
\hline \multirow[b]{2}{*}{ Outcome after seeing a dietitian ... } & \multicolumn{5}{|c|}{ How important is this outcome? } \\
\hline & $\begin{array}{c}\text { Not } \\
\text { at all } \\
1\end{array}$ & 2 & 3 & 4 & $\begin{array}{c}\text { Very } \\
5\end{array}$ \\
\hline 1. I will feel less tired & & & & & \\
\hline 2. I will feel better able to cope with nausea & & & & & \\
\hline 3. My appetite will improve & & & & & \\
\hline 4. I will have less diarrhoea & & & & & \\
\hline 5. I will have less constipation & & & & & \\
\hline 6. My skin will be less itchy & & & & & \\
\hline 7. I will sleep better & & & & & \\
\hline 8. I will be able to concentrate better & & & & & \\
\hline 9. Overall, I will feel better able to cope & & & & & \\
\hline 10. I will need less medication & & & & & \\
\hline 11. I will be stronger if I need surgery in the future & & & & & \\
\hline
\end{tabular}

Domain 6: The experience of seeing a dietitian

\begin{tabular}{|c|c|c|c|c|c|}
\hline \multirow[b]{2}{*}{ Outcome after seeing a dietitian ... } & \multicolumn{5}{|c|}{ How important is this outcome? } \\
\hline & $\begin{array}{c}\text { Not } \\
\text { at all } \\
1\end{array}$ & 2 & 3 & 4 & $\begin{array}{c}\text { Very } \\
5\end{array}$ \\
\hline 1. I will set my own goals for good nutrition & & & & & \\
\hline 2. The dietitian will set nutrition goals for me & & & & & \\
\hline 3. Together, the dietitian and I will set nutrition goals & & & & & \\
\hline 4. I will learn new information from the dietitian & & & & & \\
\hline 5. I will receive useful written information about my die & & & & & \\
\hline 6. I will be able to do something differently & & & & & \\
\hline 7. I will feel reassured & & & & & \\
\hline 8. I will feel confident in managing my condition & & & & & \\
\hline 9. I will be pleased with my progress & & & & & \\
\hline 10. The dietitian will be pleased with my progress & & & & & \\
\hline 11. Other health staff will be pleased with my progress & & & & & \\
\hline
\end{tabular}

\section{About you}

How old are you?

Are you male / female? (please circle)

1. Do you live in the UK? Yes/No (please circle)

2. Is English your first language? Yes/No (please circle)

3. Are you...

A person with liver disease?

A carer for a person with liver disease

A healthcare professional working with people with liver disease? Other (please specify) 


\title{
Questions for people with liver disease
}

1. What is the main liver condition that you suffer from? (please tick)

Alcohol-related liver disease

Autoimmune hepatitis

Benign tumours and cystic disease

Budd chiari

Cirrhosis

Fatty liver and non-alcoholic steatohepatitis

(NASH)

Gallstones

Gilbert's syndrome

Haemochromatosis

Hepatitis A
Hepatitis B

Hepatitis C

Hepatitis D or E

Liver cancer

Obstetric cholestasis

Porphyria

Portal hypertension

Primary biliary cirrhosis

Primary sclerosing cholangitis

Wilson's disease

Other (please specify)

2. How many years have you suffered from it?

3/4. What do you consider is your main and second most important nutritional problem if you have one? (please tick one in each column)

\begin{tabular}{|l|l|l|} 
& Main nutritional problem & Second most important problem \\
\hline No nutritional problem & & \\
\hline Underweight & & \\
\hline Overweight & & \\
\hline Difficulty eating & & \\
\hline Trying to follow a special diet & & \\
\hline Other (please specify) & &
\end{tabular}

5. Please score how important you think nutrition is in liver disease on a scale of 1 (very important) to 5 (not important at all) - please circle one number
1
2
3
4
5

6. Please score your health today on a scale of 1 (perfect health) to 5 (very ill) - please circle one number

$\begin{array}{lllll}1 & 2 & 3 & 4 & 5\end{array}$

7. Have you ever seen a dietitian for one-to-one advice about your liver condition? (please tick)

Yes (please go to question 8)

No (please go to page 10)

8. How many times have you seen a dietitian for your liver condition in the last five years?

9. Has anyone else given you advice about eating or nutrition relating to your liver condition? (tick all that apply)

\author{
Nurse \\ Hospital doctor \\ GP \\ Pharmacist \\ Other healthcare professionals \\ Other patients \\ Other, please specify
}




\section{Appendix B}

\section{Framework (thematic) analysis}

Breakdown of additional themes/dietetic health outcomes derived using framework analysis on free-text responses to questionnaire.
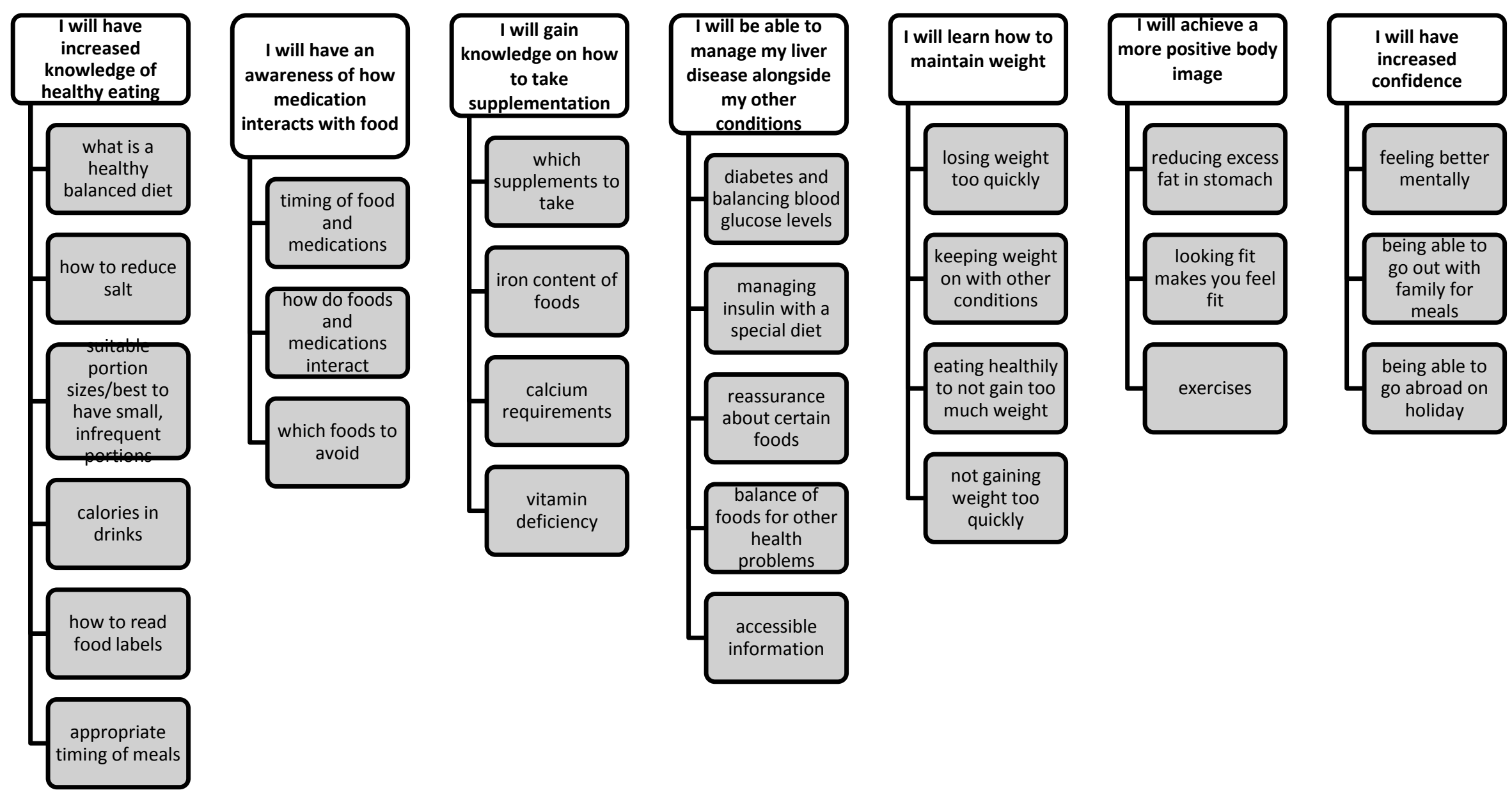